\title{
Bharath Sriraman and Lyn English: Theories of mathematics education: seeking new frontiers. (Springer series: advances in mathematics education)
}

\author{
Springer ISBN: 978-3-642-00741-5, 2010, XXX + 668 pp., hardcover, $\$ 129.00$
}

\author{
Alan H. Schoenfeld
}

Accepted: 6 June 2010/Published online: 13 June 2010

(C) The Author(s) 2010. This article is published with open access at Springerlink.com

Many years ago, I had the good fortune to board an airplane flight across the USA and find both Jim Greeno and David Clarke on the plane. The three of us quickly retired to the back of the airplane, where we had a wide-ranging conversation for more than $5 \mathrm{~h}$. We talked about our different theoretical orientations to looking at classrooms. Clarke was involved in the study of student understanding; I was trying to model teaching; Greeno was focusing on the classroom community. As we discussed each other's work, we pursued points of commonality and difference, and the strengths and limitations of the approaches we had taken. (None was adequate to explain everything; each explained something that the others did not.) As always, a few people stood around the back of the plane, some stretching or otherwise occupied.

At the end of the flight, the seat belt sign came on, and the three of us shook hands and prepared to go on our way. At that point, one of the bystanders came up to us and said, "Thank you so much. That was an absolutely wonderful seminar. I learned a great deal from your exchanges."

I had precisely that kind of feeling when I finished reading Theories of Mathematics Education: Seeking New Frontiers. This rather substantial volume is organized into 19 parts, each of which, after the initial overview ("Surveying theories and philosophies of mathematics education," by the editors), typically contains a brief preface, a substantial essay, and from one to three commentaries on the essay. Thus, the book can be seen as a series of dialogs among some of the top professionals in the field, to which

A. H. Schoenfeld ( $\square)$

Education, EMST, University of California,

Tolman Hall \# 1670, Berkeley, CA 94720-1670, USA

e-mail: alans@berkeley.edu readers have the privilege of "listening in." This is an excellent format, one that is extremely well suited for discussions of theory. When issues are "settled," a set of definitive, handbook-like chapters may be appropriate. But when ideas are being sorted out, a set of dialogs helps to reveal more of the unsettled (as well as the settled) terrain. That is a good thing.

To begin at the beginning, Jeremy Kilpatrick notes in his preface to Part I (the survey by the editors mentioned above) that Europeans have, in general, been more explicit and reflective about issues of theory than have those in the USA. Thus, the international authorship of the book brings value added to the American context. Kilpatrick mentions, among other things, the need for greater clarity about the relationship between theories and models, a point to which I shall return: as a reviewer I cannot resist the temptation to enter into the dialogs begun by the authors.

The volume itself offers a tapestry of theory-related issues in mathematics education: some closely related, some parallel, and some orthogonal. Although there are no formal section breaks in the book, there is a tacit organization in the order of the chapters, with the more broadly theoretical and metatheoretical chapters coming in Parts I through $\mathrm{V}$, and a broad range of issues-oriented theoretical chapters in the sequel.

The volume begins with various perspectives on the "big picture." Sriraman and English, citing Lincoln and Guba (1994), reference some of the themes mathematics education should address:

1. What is reality? Or what is the nature of the world around us?...

2. How do we about knowing the world around us?...

3. How can we be certain in the "truth" of what we know? (p. 7) 
They proceed with an interesting selection and organization of main themes, e.g., "Imre Lakatos and the Various Forms of Constructivism," in which the argument is made that "Proofs and Refutations [Lakatos, 1976] may very well serve as a basis for a philosophy of mathematics, which in turn can be used as a basis to develop a theory of learning such as constructivism." This is an overstatement: the underpinnings of constructivism are clearly empirical, at least for the vanilla version of constructivism, which is based on the claim that we humans construct our interpretations of the world around us, rather than perceiving reality directly (We could not be taken in by optical illusions if we perceived "reality" directly.) For me, there is an interesting issue of the parallels between the very human (and fallible) constructions of mathematics revealed in Proofs and Refutations, as opposed to a Platonic "it's there to be discovered" view, and the central thesis of constructivism as a denial of naïve realism. Moreover, which theory is the chicken and which is the egg is open to question. But, you see, I am arguing with the authors. They have drawn me into conversation.

Part II, "Reflections on Theories of Learning" (Paul Ernest) and Part III, "On the Theoretical, Conceptual, and Philosophical Foundations for research in mathematics Education (Frank Lester)" continue with the big picture. These, with Parts IV, "Theories of mathematics Education: Is Plurality a problem?" (Stephen Lerman), and V, "Reconceptualizing Mathematics Education as a Design Science" (Richard Lesh and Bharath Sriraman) can be considered as the "Framing" section of the volume. The territory covered is both broad and eclectic.

The question of plurality raised in Lerman's essay merits some attention, because how one frames the question is consequential. Lerman's chapter is based on an empirical study in which he employs Bernstein's (1999, 2000) characterization of research discourses to trace the evolution of the field. He concludes that a multiplicity of theories and debates is neither surprising nor troubling in itself, although he is troubled (as am I) by the superficial use of theories and methods, where more nuance is essential. But there is another way to think about theories and methods, one which helps to explain the polyvocal character of this volume and the field, and which would help to put the chapters (and the theories) in perspective.

To put things simply, the function of a theory is to explain how something (or some collection of things) works. Thus, number theory is aimed at explaining a specific body of mathematical phenomena; the theory of complex variables is aimed at explaining something else. They overlap when complex functions are useful for the study of particular issues in number theory, but it is absurd on the face of it to think of one as subsuming the other, or of the theories competing with each other in some way. In physics, there are candidates for grand theories, such as Newton's; but by and large, grand theories are not of tremendous value when one is trying to work on particular problems, such as designing a fuel-efficient airplane. In that context, much more narrowly defined theoretical ideas pertaining to aerodynamics, stress analyses, and material science are useful.

The question for our field is: what are the phenomena that research in mathematics education sets out to explain? To the degree that there are different classes of phenomena, there will be different theoretical lenses, perspectives and methods. Mathematics education writ large encompasses many different concerns and classes of phenomena. For example, a far from exhaustive list of fundamental concerns in mathematics education includes:

- Epistemology

- Cognition: how does the mind work? What can be said about memory, learning and cognitive architecture?

- Content understanding: what does it mean to "understand" fractions or linear functions?

- Pedagogy: what are effective teaching methods? (and by what standards?)

- Equity and social justice; more generally, issues of policy

- Teacher knowledge; teacher decision making.

It is no more reasonable to expect one theory of mathematics education to deal effectively with this range of phenomena than it is to expect one theory of physics to deal effectively with issues of kinematics, electricity and magnetism, and stress analyses. Moreover, adherence to grand educational theories (e.g., cognitive science "vs." situated cognition or social cognition or...) is problematic for the field: "theory wars" come largely from researchers missing the fact that different theories are of differential utility in different contexts (see Burkhardt \& Schoenfeld, 2003).

At the core of Part V is Lesh and Sriraman's "Reconceptualizing Mathematics Education as a Design Science": an interesting and provocative piece that stimulates three full reaction chapters. The content of Lesh and Sriraman's chapter is, in many ways, consistent with the discussion in the previous few paragraphs; thus, I find the title somewhat ironic, given the linguistically monolithic character of a "reconceptualizing." I think "On Mathematics Education as a Design Science" would have done. The authors point out, rightfully, that much work in mathematics education (in the USA at least; as Kilpatrick points out, other continents seem to have taken theory more seriously) is ideologically driven: that people swear allegiance to grand theories, and that such grand theories are not often useful for instructional purposes. I do differ from the authors in terms of terminology; their characterization of "models" as "purposeful/situated/easily modifiable/shareable/re-usable/ 
multi-disciplinary/multi-media chunks of knowledge" (p. 143) is non-standard and problematic. I prefer the standard scientific use of the term and the use of "local theories" and "local models" to characterize particular situations (see, e.g., Cobb, Confrey, diSessa, Lehrer \& Schauble, 2003).

In any scientific field (e.g., as in the physics example given above), there are many, often overlapping theories. Generally speaking, the smaller the scope of a theory the more precisely it can be expected to characterize a particular set of circumstances, e.g., Hooke's law applies to a relatively small class of phenomena, but it should (once the parameters of a particular situation are described) characterize those phenomena quite well. A theory describes a general set of relationships among objects and applies to a wide range of situations. Thus, for example, Newton's gravitational theory specifies the gravitational forces between objects, given their masses and the distances between them. The theory itself is posited to apply to a wide range of situations, e.g., to a two-body system such as the earth and the moon, and a more complex system such as our solar system. This is where models come in. A model is a theory-driven representation of a particular situation: the theory says what information needs to be specified in the model and how the objects represented in the model relate to one another. Thus, a model of lunar motion around the earth is obtained by specifying the masses of the earth and the moon, their positions and velocities, and the distance between them; one then applies the theory to the model to obtain a dynamic characterization of the system. Similarly, a model of the motion of the planets is obtained by specifying all of the parameters in the theory. One checks the accuracy of a model by comparing the behavior of the model with the behavior of the system being modeled; one tests the scope of the theory by examining the range of situations that have been successfully modeled. This is the approach I took in developing a theory of teaching in context (Schoenfeld, 1998; 2010; see also Günter Törner, Katrin Rolka, Bettina Rösken and Bharath Sriraman's chapter "Understanding a teacher's actions in the classroom by applying Schoenfeld's theory Teaching-in-context: Reflecting on goals and beliefs," in the volume under review). The theory specifies the character of an individual's in-the-moment decision making, on the basis of the teacher's resources (primarily knowledge), goals, and orientations (an abstraction of beliefs). Over more than a decade, the theory was used to construct models of individual teachers who varied widely in their attributes, from a beginning teacher teaching a highly structured traditional lesson to an experienced third grade teacher teaching a lesson in which the classroom agenda was co-constructed by teacher and students. This kind of theory testing by model building is the modus operandi of the sciences, and we would do well as mathematics educators to follow suit.

The balance of Theories of Mathematics Education: Seeking New Frontiers offers a cornucopia of perspectives and frameworks, ranging from the epistemological (as in Stephen Campbell's "Embodied Minds and Dancing Brains: New Opportunities for Research in Mathematics Education") to the political (as in Bharath Sriraman, Matt Roscoe, and Lyn English's "Politicizing Mathematics Education: Has Politics Gone Too Far? Or Not Far Enough?"), with stops along the way for explorations of the tacit ("Knowing More Than We Can Tell" by Nathalie Sinclair), of concept construction ("The Fundamental Cycle of Concept Construction Underlying Various Theoretical Frameworks" by John Pegg and David Tall), of "Feminist Pedagogy and Mathematics," (with essays by Judith Jacobs, Gilah Leder, Safure Bulut, Bekir Gür and Bharath Sriraman, Gü $\delta$ björg Pálsdóttir and Bharath Sriraman), and more.

The perspectives are often eclectic, as in both of the main essays devoted to problem solving, Gerald Goldin's "Problem Solving Heuristics, Affect, and Discrete Mathematics: A Representational Discussion" and Lyn English and Bharath Sriraman's "Problem Solving for the 21st Century." Both essays start with the fact that problem solving has not had the "traction" it should have had in curricular terms: although enough was known by the late 1980s to embark on a program of teaching problem-solving strategies, this kind of focused intellectual work was never undertaken on a large scale. Neither essay helps to explain why (at least in the USA; I hesitate to discuss curricula outside the USA) that is the case.

What one sees in the USA is an interesting form of curricular mutation and the impact of the reward system in academia. By the late 1980s, the core research in problem solving had been done; what remained to be done was an applied program of research and development, fleshing out the core ideas and applying them to curriculum development. As discussed in Burkhardt \& Schoenfeld (2003), curriculum development gets very little credit at research universities in the USA; one would not expect research faculty to engage directly in such work. Moreover, there is little glamor in pursuing research directions that have been laid out by others; thus researchers tend to move into new areas where they can stake a claim for new ideas. This is one reason for the sharp drop in research on problemsolving heuristics noted by the authors.

But, problem solving did not disappear; rather, it transmuted (in the USA), in a way entirely consistent with the "loosely coupled" system in the USA: a system that operates in a very different way than more centralized European and Asian educational systems, where "top down" mandates from educational ministries play a very 
strong role in determining curricula. In the USA, the 50 states have largely independent educational systems and, within them, the 15,000 school districts have varied degrees of autonomy in setting educational goals and standards. What happened in the USA was that the National Council of Teachers of Mathematics issued the 1989 Curriculum and Evaluation Standards for School Mathematics: a document that was deeply influenced by the research of the previous decades and which identified four cross-cutting curricular goals at all levels: problem solving, reasoning, communication, and connections. Recognizing that commercial textbook manufacturers would not produce books consistent with the Standards (publishers thought it too great a financial risk to invest in something new without a guaranteed market), the US National Science Foundation funded a significant amount of "Standards-based" curriculum development. Now, almost 20 years later, many of those curricula, which interpreted "problem solving" to mean "introducing and teaching typical mathematical content through meaningful problems", hold a significant part of the textbook market. Thus, "problem solving" did not disappear; it mutated.

It goes without saying that curricula could be enlivened with more interesting tasks, with a greater focus on sense making, and with a more coherent attempt to build problem-solving skills: not as "add-ons" but as a core component of mathematical activity. I believe that some curricula, internationally and in the USA, are aimed at doing so. As technological tools become increasingly available, such tools should be used in the service of mathematics learning. (Here is one trivial example. When I was a college student the numbers in my statistics textbooks were chosen so that the variances of data distributions were always perfect squares. After all, we had to take the square roots of those numbers by hand to find the standard deviations of the distributions. Today, students can explore the distributions of a wide range of real-world phenomena; computing statistical parameters is done trivially by machine. Hence problems can be more meaningful, and the focus can be on sense making.) But, an emphasis on discrete mathematics as a shift of focus and as a solution to the "affect problem," with a focus on representations (Goldin's chapter) strikes me as somewhat peripheral to the main issues of mathematical thinking and problem solving. Also, I do not have anything against mathematical modeling, a focus of English and Sriraman's chapter; modeling is an essential form of sense making using mathematics. But as explained above, an argument grounded in the failure of attempts to teach problem solving is somewhat misplaced. Moreover, there is an extensive interdisciplinary literature on problem-based learning, which is compatible with the ideas expressed. There have been arguments for some years that a form of "functional mathematics" grounded in the mathematical analysis of real-world issues (e.g., risk) should play a central role in the curriculum (see, e.g., Burkhardt \& Pollak, 2006).

You see, the authors have done it again. They have drawn me into dialog. These chapters, very much unlike the "definitive" chapters in handbooks, are opinionated and provocative. The commentaries further open space for conversation and the reader is drawn in. The scope of the book is huge; I have not had space in this review to consider the three chapters on network theory, the chapter on proof and more. This is so diverse a collection of chapters that every reader is guaranteed to find discussions of some areas that are at most barely familiar. Established researchers will find themselves provoked to react to various perspectives; those embarking on their careers will find introductions to a wide range of areas. All will be provoked to react, and that kind of engagement is a fitting reward for reading the book.

Open Access This article is distributed under the terms of the Creative Commons Attribution Noncommercial License which permits any noncommercial use, distribution, and reproduction in any medium, provided the original author(s) and source are credited.

\section{References}

Bernstein, B. (1999). Vertical and horizontal discourse: An essay. British Journal of Sociology of Education, 20(2), 157-173.

Bernstein, B. (2000). Pedagogy, symbolic control, and identity (revised ed.). Maryland: Rowman and Littlefield.

Burkhardt, H., \& Pollak, H. (2006). Modelling in mathematics classrooms: Reflections on past developments and the future. ZDM, 38(2), 178-195.

Burkhardt, H., \& Schoenfeld, A. H. (2003). Improving educational research: Toward a more useful, more influential, and better funded enterprise. Educational Researcher, 32(9), 3-14.

Cobb, P., Confrey, J., diSessa, A., Lehrer, R., \& Schauble, L. (2003). Design experiments in educational research. Educational Researcher, 32(1), 9-13.

Lakatos, I. (1976). Proofs and refutations. Cambridge: Cambridge University Press.

Lincoln, Y. S., \& Guba, E. G. (1994). Competing paradigms in qualitative research. In N. K. Denzin \& Y. S. Lincoln (Eds.), Handbook of qualitative research (pp. 105-117). Thousand Oaks: Sage.

National Council of Teachers of Mathematics. (1989). Curriculum and evaluation standards for school mathematics. Reston: Author.

Schoenfeld, A. H. (1998). Toward a theory of teaching-in-context. Issues in Education, 4(1), 1-94.

Schoenfeld, A. H. (2010). How we think: A theory of human decision-making with educational applications. New York: Routledge (in press). 